\title{
An Anemometer for I.L.L. Winds
}

\begin{abstract}
What factors govern interlibrary loans? Recording interlibrary loan transactions on punched cards makes possible analysis of such factors as type of material requested, form of material received, transaction time, failure to receive material, and type of library involved. The results of a two-year study of such a system are presented, and some conclusions are drawn about interlibrary loan.
\end{abstract}

I NTERLIBRARY LOAN has long been an essential library function. As the publication mass grows larger and larger, the ability of any one library to meet its users' needs within its own collection becomes less and less. In 1964 Pings and Orr estimated that two million dollars annually were spent on the interlibrary loan operation in the biomedical library network. ${ }^{1}$ In 1967 the Medical Library Association reported an annual volume of over one million transactions.:

Although these transactions represent a significant national expenditure of time and money, they have infrequently been analyzed. Undoubtedly the major cause of this failure has been the difficulty inherent in handling massive mounds of clumsy paper records. Data processing techniques, however, can now replace these records with machine readable

\footnotetext{
1 R. H. Orr and V. M. Pings, "Document Retrieval; the National Biomedical Interlibrary Loan System and Interlibrary Loans," Federation of American Societies on Experimental Biology Proceedings, XXIII (September 1964), 1155-63.

${ }^{2}$ Committee on Surveys and Statistics of the Medical Library Association. "Library Statistics of Schools in the Health Services": Part II, Bulletin of the Medical Library Association, LV (April 1967), 178-82.
}

Mrs. Atwood is Director of Information Services, Medical Library, University of Louisville. The author acknowledges the assistance of her colleagues, Mrs. Mary Stahl and Mrs. Kay Shotts, in carrying out this study. files. The clerical capability of these files in producing many forms of printouts from a single record is easily and frequently exploited. Their analytical capability is an extremely powerful tool that needs to be more widely used. Once a function can be defined in quantitative terms, working methods can be experimentally manipulated to determine the most efficient procedures. The University of Louisville medical library's interlibrary loan operations are a microcosm illustrating the application of both of these capabilities to an actual library function.

In 1965 the interlibrary loan traffic in the University of Louisville medical library had reached a thousand out-oftown transactions annually, a twentyfold increase in a decade. In July of that year the library began to record its transactions on IBM cards, maintaining two card files. The first is a detail file containing a card for each transaction. When a request is initiated, either by another library or by a local user, the interlibrary loan assistant records it on a form sheet. The first entry consists of a transaction number, title, and codes for the library, borrower, form of material requested, and request method. Transaction time, form of material received, and charges are added when the transaction is completed. If the material 
requested is not received, the reason for failure is recorded; the loan is requested again using the same transaction number, with subnumbering counting the number of repetitions. The second file lists the libraries involved in the detail file. Each card contains the library's code number, name, and codes for its geographical location, distance from Louisville, size, type, teletype use, and fee policies. Maintenance of these two files is easy and inexpensive. Two hours of keypunching weekly keeps them current. These files are used clerically in many ways.

At the weekly updating of the detail file a list of incomplete loans is printed in transaction number order. This list gives an up-to-date, easily accessible record of tardy receipts that need followup. The previous time-consuming search for these items through the bulky old file has been eliminated.

These files, together with borrower files, produce a variety of printed lists.

1. Summary counts of borrow and loan transactions by individual library, type of library, type of material requested (these counts include data on loan repetition), method of request (this measures growth of the TWX installation), form received or set, reasons for failure to receive material.

2. Analysis of borrowing population by individual borrower, borrower category (e.g. faculty, graduate student, etc.), departmental category (e.g. anatomy, biochemistry, etc.), failure to obtain material for user after repetitive requests.

3. Financial analysis-charges for material, TWX costs.

4. Title analysis-alphabetical listing of book and journal requests.

These clerical productions are very helpful. They have made routine daily operations more efficient. They have also given a complete and detailed view of the interlibrary loan function. Patterns of use are discernable so that for the first time planning for the future can be done on a sound basis.

The analytical capability of these files is astonishing. These records contain quantitative measurements of interlibrary loan characteristics. Investigations have led to changes in routines that greatly improve service. They have also engendered a new concept of the role of the interlibrary loan in the total library function.

These analyses have been completed in several ways. Investigations were first performed on a sorter and calculated on an adding machine. It is not necessary to use a computer for the initial analysis. A preliminary trial with small samples and simple machines leads to the thorough understanding of problems and desired solutions that is a prerequisite to computer programing. What affects transaction time? Can it be manipulated to improve service?

A thirty month sample of sixteen hundred records was first submitted to Chi Square and Rho analysis at the University of Louisville medical school computer center. Loans to other libraries and local borrowings were not included in the sample. All the recorded factors were found to affect transaction time significantly. After consulting with statisticians, the data were divided into three time periods and average transaction times were compared within each descriptive group. ${ }^{3}$

The time periods are constant for each set.

Period 1: July 1965-June 1966

Period 2: July 1966-June 1967

Period 3: July 1967-December 1967

The descriptive groups, varying for each set, may be divided into two sections, the first containing uncontrollable

\footnotetext{
${ }^{3}$ Ronald Kelsay, Director Computer Service, University of Louisville Medical School; Cornelius Mack, Reader in Applied Mathematics, Institute of Technology, Bradford, England. Personal communications.
} 
factors, and the second containing controlled factors.

\section{UnControllable Factors}

Form of material requested. (This is controlled by users.)
1. Book
2. Journal
3. Thesis

Form of material received. (This is controlled by the lending library.)
1. Photocopy

2. Original

3. Microfilm

The results of these analyses may be summarized in the following tables.

There is no significant difference in book and journal transaction time, but theses are significantly slower. This may be related to the form of material received as shown in Table 1.

Originals and photocopies are de-

TABLE 1

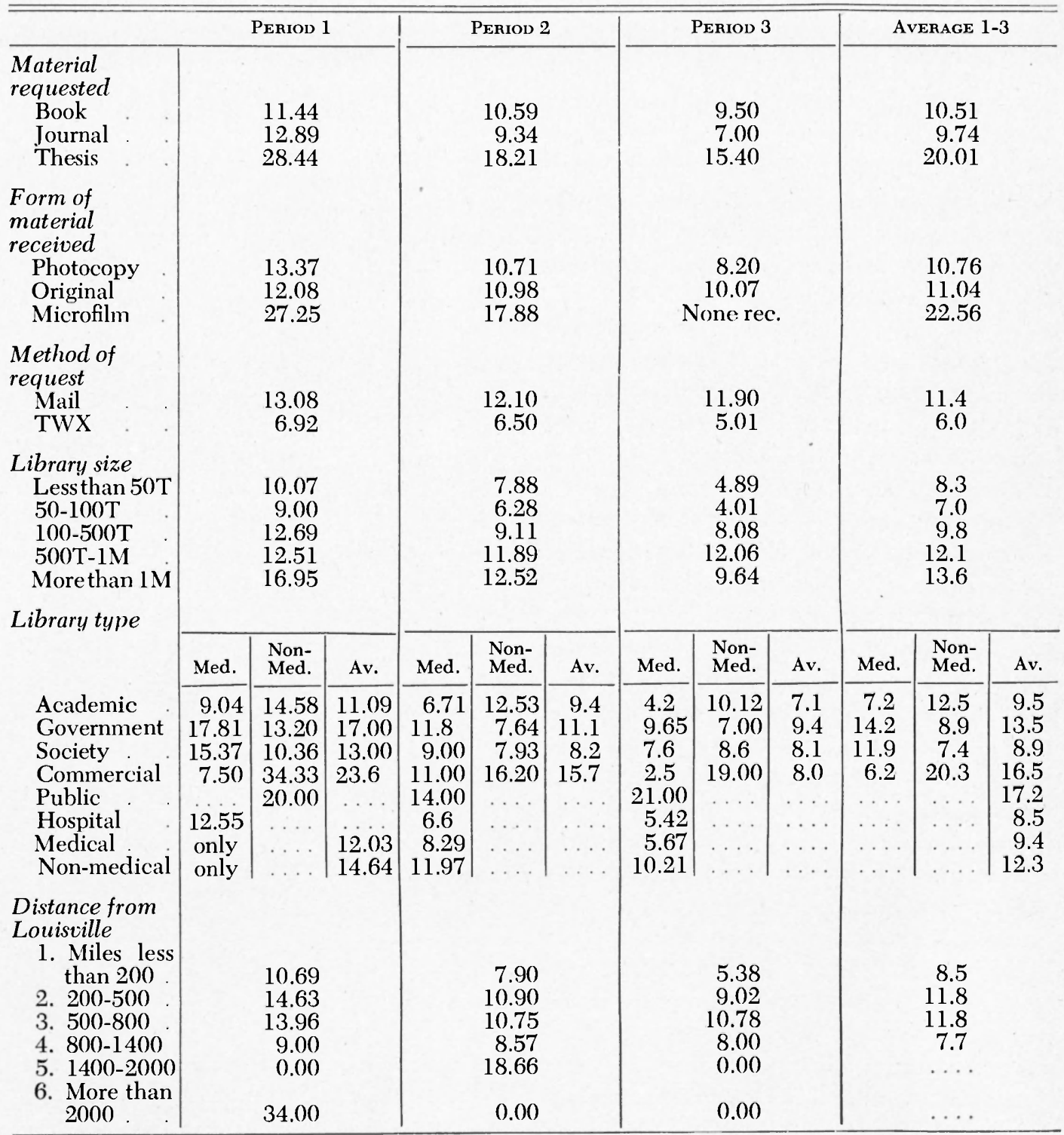


TABLE 2. Reasons for Failure to Complete Loans

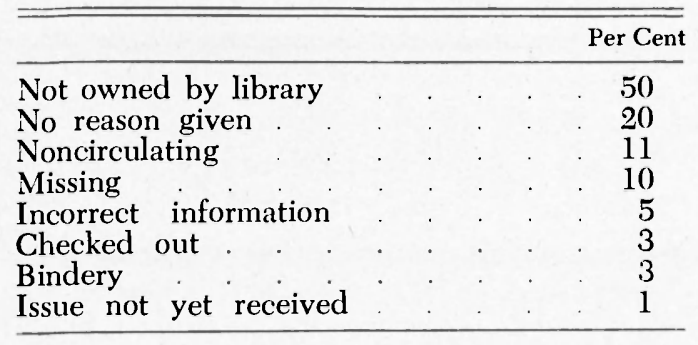

livered at about the same rate, while microfilm is considerably slower. The customary microfilming of theses apparently accounts for their delayed delivery. Fortunately, the numbers of these dilatory theses are relatively few, accounting for only 2 per cent of the borrowing. Photocopy has become the usual method of journal transmission. Original volumes are still mailed when the articles desired are very lengthy, difficult to copy, or when the borrower wishes to examine the entire volume.

In the great majority of transactions the transaction time was unaffected by these uncontrollable factors. This analysis, however, led to another disheartening discovery. The inefficiency of the interlibrary loan became concretely and horribly apparent. In a two-year period the "first attempt" book failure rate was 37 per cent, and the journal failure rate 19 per cent. Furthermore, Louisville gave no better service to libraries borrowing from it. Louisville failed to mail 70 per cent of the books and 23 per cent of the journals it was asked to loan. The cumulative failure rate for all transactions was 31 per cent. When this failure rate persisted over a two-year period, the reasons for failure were sought. The reason for Louisville's failure to lend are given in Table 2 .

It is obvious that although union lists do lower the failure rate for journals in comparison with books, they do not eliminate failure completely. A completely accurate union list compiled on Dily
$\mathrm{X}$ will not reflect the reality of any working library's collection on Day Y. These are powerful reasons for the establishment of central collections whose only function is interlibrary loan. The obvious obverse is the questionable utility of the publication of huge, detailed holdings statements in Union Lists.

\section{Controllable Factors}

Manipulation of the second group of characteristics, those within control, has led to dramatic improvements in service.

Method of request

1. TWX

2. Mail

Characteristics of lending library

1. Size in number of volumes:
a. 50,000
b. $50,000-100,000$
c. $100,000-500,000$
d. $500,000-1,000,000$
e. $1,000,000$

2. Type of library:

a. Medical
(1) Academic
(2) Government
(3) Society
(4) Commercial
(5) Hospital

b. Non-medical
(1) Academic
(2) Government
(3) Society
(4) Commercial
(5) Public

3. Distance from Louisville:
a. 200 miles
b. $200-500$ miles
c. $500-800$ miles
d. 800-1,400 miles
e. 1,400-2,000 miles
f. 2,000 miles

The analytical results expressing the effect of these factors is summarized in Table 1.

The improvement in service due to TWX justifies the annual thousand-dollar 
investment in the system. The rapidity of the negative reply counts heavily here, as a new request can be immediately initiated without further loss of time. The large number of negative replies further reinforces the importance of this factor. The permanence of this improvement has been questioned. ${ }^{4}$ Will shorter TWX transaction time persist after the glamour and novelty of a new method fade and everyone is using it? Some of the improvement has been so great that it is obvious that elimination of half of the mailing time cannot account for it. Greater attention to the request at the lending institution also plays a part. The answer is not yet clear. However, continuous monitoring of loan data will make any change immediately apparent.

The most efficient interlibrary loan library is one of $50,000-100,000$ volumes. After that the familiar phenomenon of the inefficient giant appears.

The types displayed in order of efficiency are:

1. commercial-medical

2. academic-medical

3. society-nonmedical

4. hospital

5. government-nonmedical

6. society-medical

7. academic-nonmedical

8. government-medical

9. public

+ Vern Pings, Wayne Medical Library; Estelle Bredman, Washington University of St. Louis Medical Library, personal communications.
TABLE 4. Thansaction Days, FoRM OF RECEIPT

\begin{tabular}{l|r|r|r}
\hline \hline Library & $\begin{array}{c}\text { Negative } \\
\text { Reply }\end{array}$ & Photocopy & Original \\
\cline { 2 - 3 } 001 & 5.0 & 9.7 & 5.5 \\
002 & 17.0 & 16.2 & 8.7 \\
013 & 7.1 & 8.5 & 14.0 \\
032 & 7.7 & 19.8 & 16.0 \\
050 & 10.5 & 22.0 & 16.1 \\
052 & 5.5 & 7.2 & 9.8 \\
100 & 20.8 & 16.0 & 11.9 \\
\hline
\end{tabular}

The distance factor gave the most startling results. It has long been a maxim that the library chosen from a union list's array should be the library geographically closest. This maxim has not been borne out by our investigations. Why should distance Zone 4 (800-1400 miles) be the most efficient? Some other factors must be cancelling out the travel time. The libraries in Distance Zone 4 are a heterogeneous group, not all medical, academic, public, or of one size.

We therefore began to investigate the possibility that the individual library's intrinsic operation is the factor of maximum force. We first arrayed libraries within the same city, using the same request method, by average transaction time. The results with distance from Louisville are shown in Table 3.

Obviously, individuality triumphs over geography in these sets. Similar variations are apparent in form of receipt arrays.

Here again in some libraries the photocopy operation is faster than wrapping and mailing the original; in others, the

Table 3. Thansaction Days, City

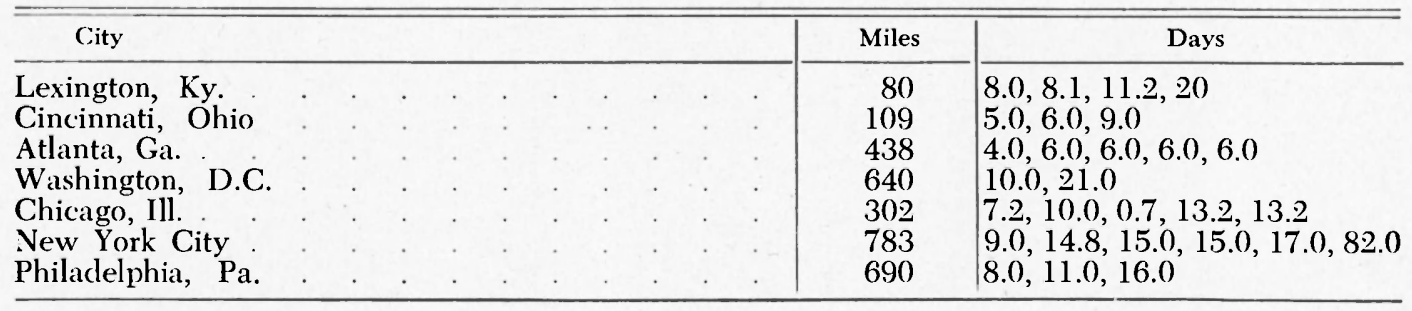


reverse is true. Checking routine for negative replies shows similar variance.

Let us now consider a further data arrangement that reinforces the conclusion that it is the intrinsic operation of each specific library, rather than any particular characteristic, that has the greatest effect on transaction time. If we arrange the average transaction time in descending order by library, we can break the data into four samples of approximately equal size, Set 1: 2-5 days; Set 2: 6-8 days; Set 3: 9-12 days; Set 4: 13-82 days. Set 1 is the most, and Set 4 the least, efficient. Analysis of the components of each set does not show groups of similar libraries within sets, but rather a heterogenous composition throughout.

We can discern here the inefficiency of large sizes.

Once we had determined the factor of maximum effect, we were able to manipulate it experimentally to improve our service. We calculated transaction times by library and arranged them in tables of descending order. The fastest times are listed first, the slowest last. The range is from 2 to 82 days. The tables are updated monthly. The request is always made from the library with the lowest transaction time. In the past six months these tables have improved our transaction time 25 per cent.

Recording our interlibrary loans on punched cards has enabled us to analyze the loan as an acquisition aid. Two excellent papers ${ }^{5}$ have already appeared indicating that the loan is useless as an acquisitions guide.

Our file was examined for repetitive requests. If we had ordered all journal titles requested during the first year, we would have added 281 titles and reduced our interlibrary loan requests that year by 29 , the second year by 37 , and in the last six months by 14 . In the second year, if we repeat the procedure, we would add 283 titles and

5 E. E. Graziano, "Interlibrary Loan Analysis," Special Libraries, LIII (May 1962), 251-7; Richard Hyman, "Medical Interlibrary Loan Patterns," Bull. Med. Libr. Assoc. LIII (April 1965), 215-24.

TABLE 5

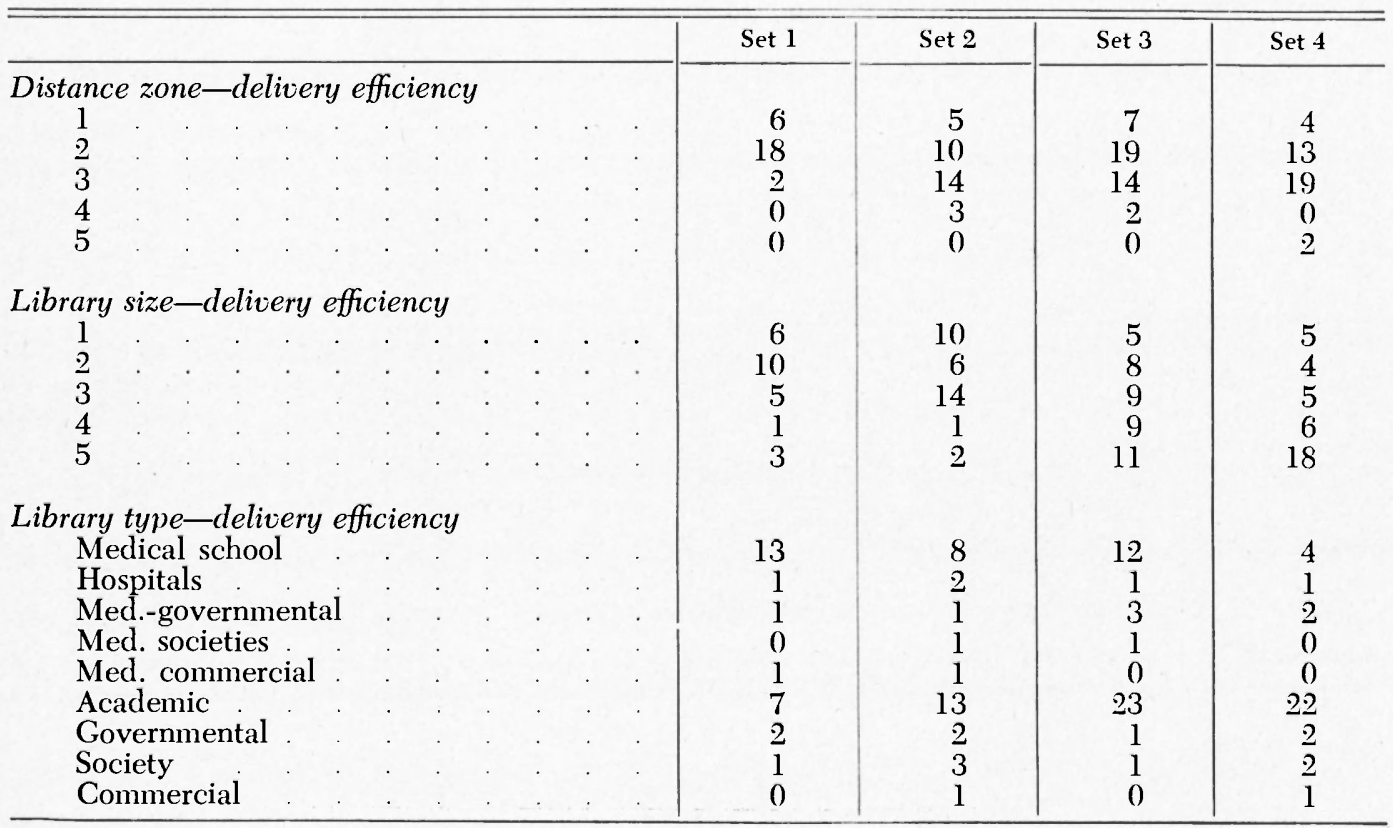


reduce our requests that year by 15 and during the next six months by 4 . The book yields were very low. Only one title out of all book requests during a thirtymonth period was asked for more than once. This is attempting to supply the user's need after he has appeared with a request we cannot fill immediately. The size of the journal title pool necessary to anticipate his needs would be astronomical. Calculations based on title number of use ratios of $7 / 1$ indicates we would have to add a pool of over two thousand titles, in an obviously futile attempt to meet our user's needs. The statistically rare event characteristic of the loan is reinforced by a subject examination. Some 80 per cent of the books asked for were out of print, and of the remainder 30 per cent were nonmedical. Similar patterns prevail in the journal requests.

In summary, data processing techniques have enabled us to examine easily and inexpensively the interlibrary loan procedures. We make no claims for the universal validity of these results. Since these methods are now available to most libraries, it would appear desirable to urge other institutions to undertake such studies. The interlibrary loan has become such a leviathan that data regarding it has become a national necessity. The small beginning at Louisville has given the administration an accurate detailed picture of this part of the library's structure. The efficiency of the interlibrary loan department has increased, and service to users has improved markedly. The necessity of the interlibrary loan has also been more clearly recognized; it can never be eliminated by increasing the size of the collection within feasible limits. The whole world is necessary as an interlibrary loan source for users. Efforts should be concentrated on more efficient access to the world rather than futile attempts to encompass it within our own respective walls.

E. E. Graziano" said five years ago in his analysis of interlibrary loan, "a quantified service will be the only hope for the libraries of 2000 A.D." These studies have proven to our satisfaction that they work extremely well in the libraries of the 1960's.

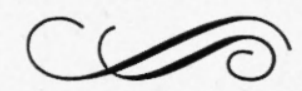

